Supporting Information

\title{
Phenylpropanoid Glycerol Glucosides Attenuate Glucose Production in Hepatocytes
}

Anne F. Murray ${ }^{1}$, Kimberly Palatini ${ }^{2,3}$, Slavko Komarnytsky ${ }^{2,3}$, Thomas J. Gianfagna ${ }^{4}$, and John P. Munafo $\mathrm{Jr}^{1 *}$

1 Department of Food Science, University of Tennessee Institute of Agriculture, Knoxville, Tennessee 37996

2 Plants for Human Health Institute, FBNS, North Carolina State University, 600 Laureate Way, Kannapolis, North Carolina 28081

3 Department of Food, Bioprocessing, and Nutrition Sciences, North Carolina State University, 400 Dan Allen Drive, Raleigh, NC 27695

4 Department of Plant Biology, Rutgers-The State University of New Jersey, 59 Dudley Rd, New Brunswick, New Jersey 08901

* Corresponding author

865-974-7247 Office / 865-974-7332 Fax

Email jmunafo@utk.edu 
Brief statement in non-sentence format listing the contents of the material supplied as Supporting Information.

- Mass spectra of each of the nine compounds identified from the blubs of L. longiflorum. 
Figure S1: ESI--MS mass spectra of compound 1 identified in L. longiflorum.

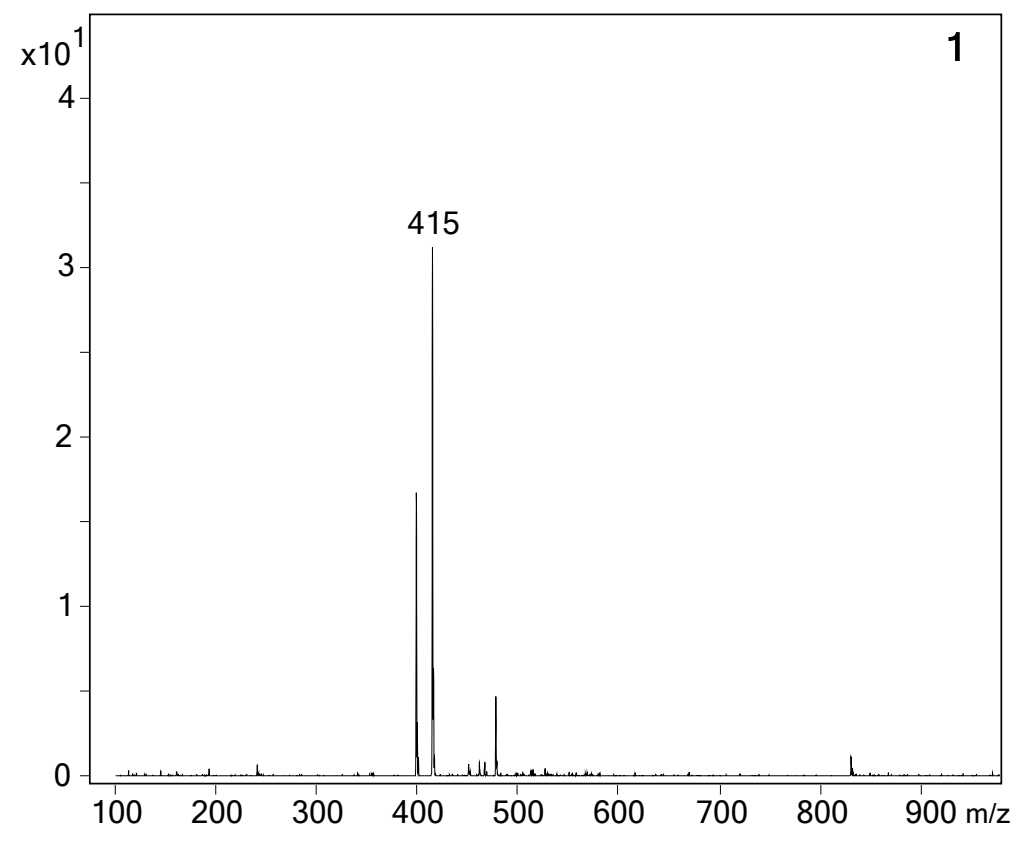


Figure S2: ESI--MS mass spectra of compound 2 identified in L. longiflorum.

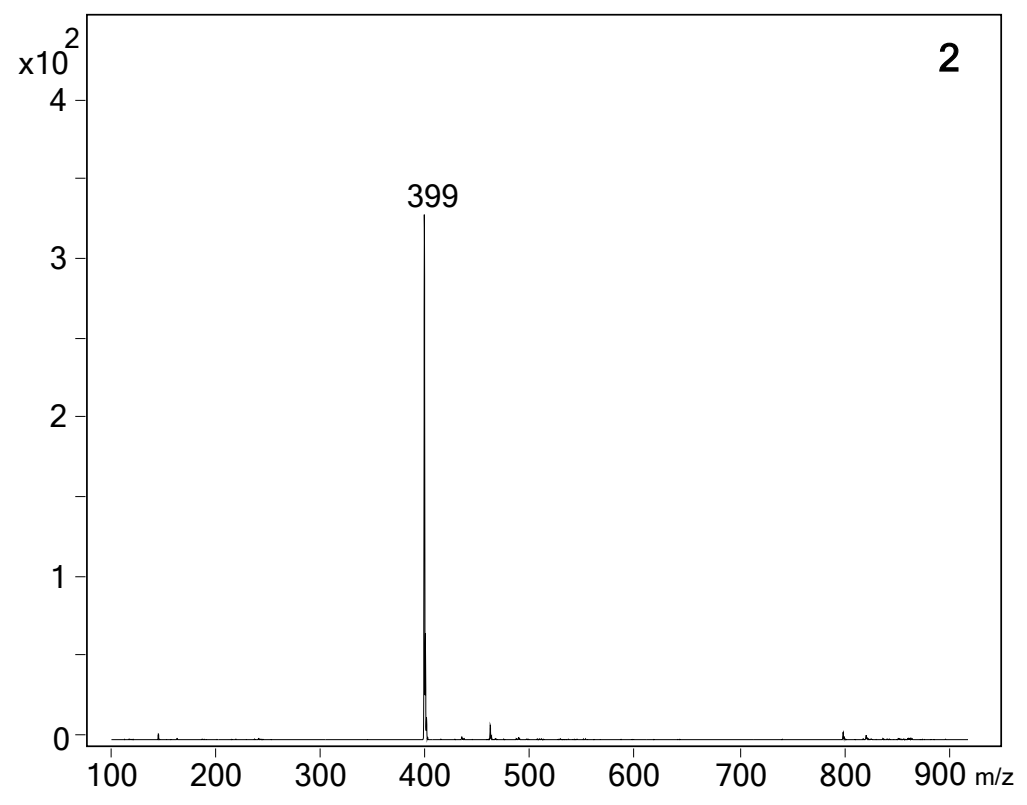


Figure S3: ESI--MS mass spectra of compound 3 identified in L. longiflorum.

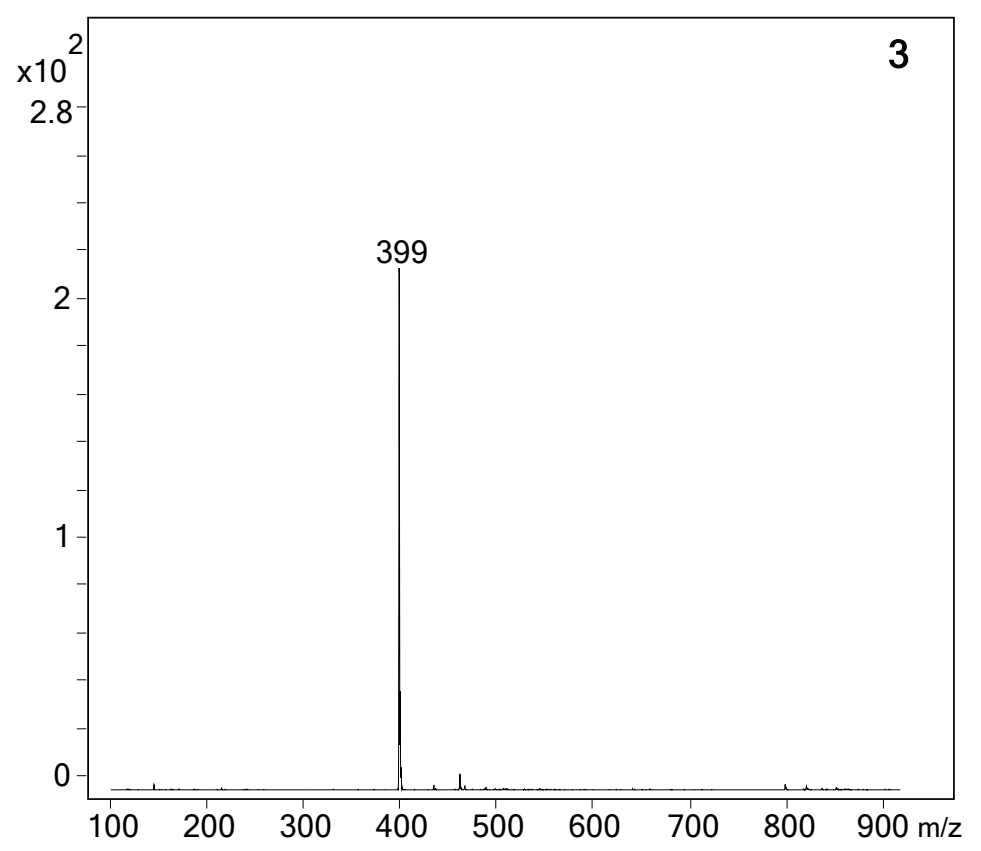


Figure S4: ESI--MS mass spectra of compound 4 identified in L. longiflorum.

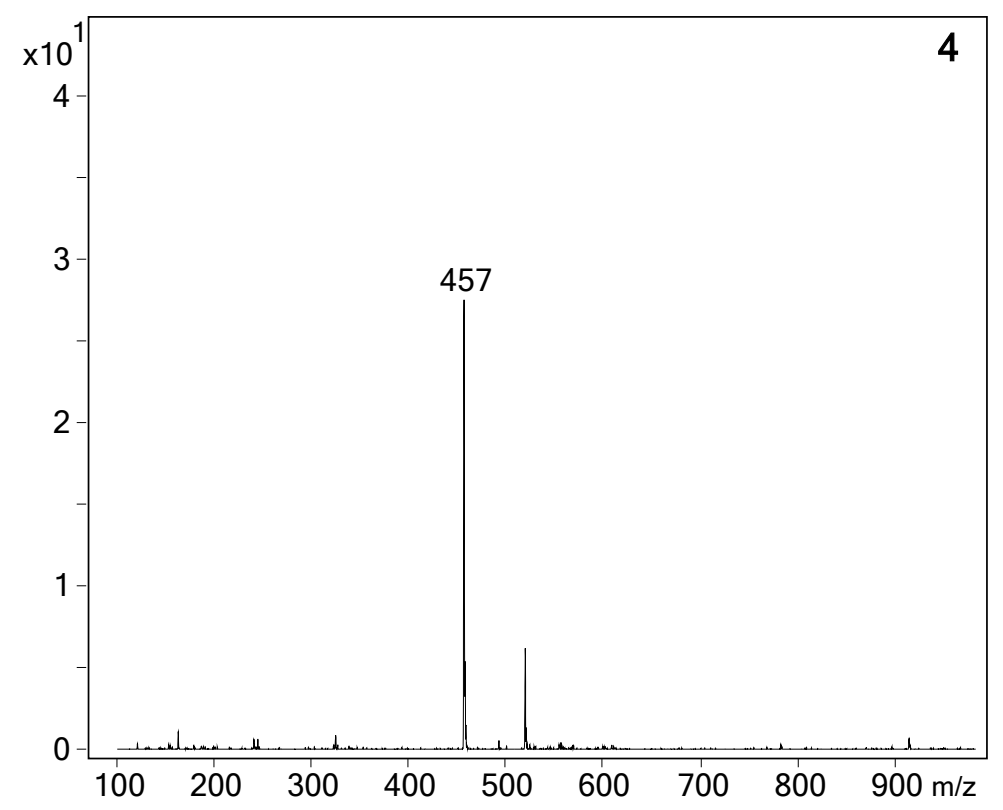


Figure S5: ESI--MS mass spectra of compound 5 identified in L. longiflorum.

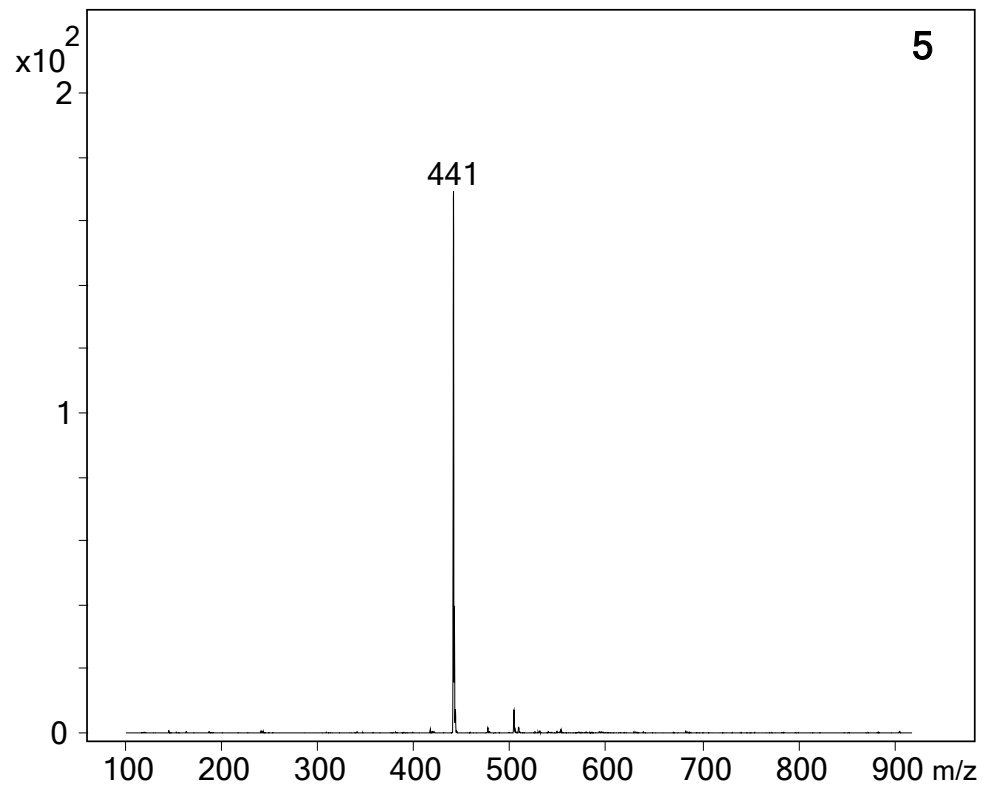


Figure S6: ESI--MS mass spectra of compound 6 identified in L. longiflorum.

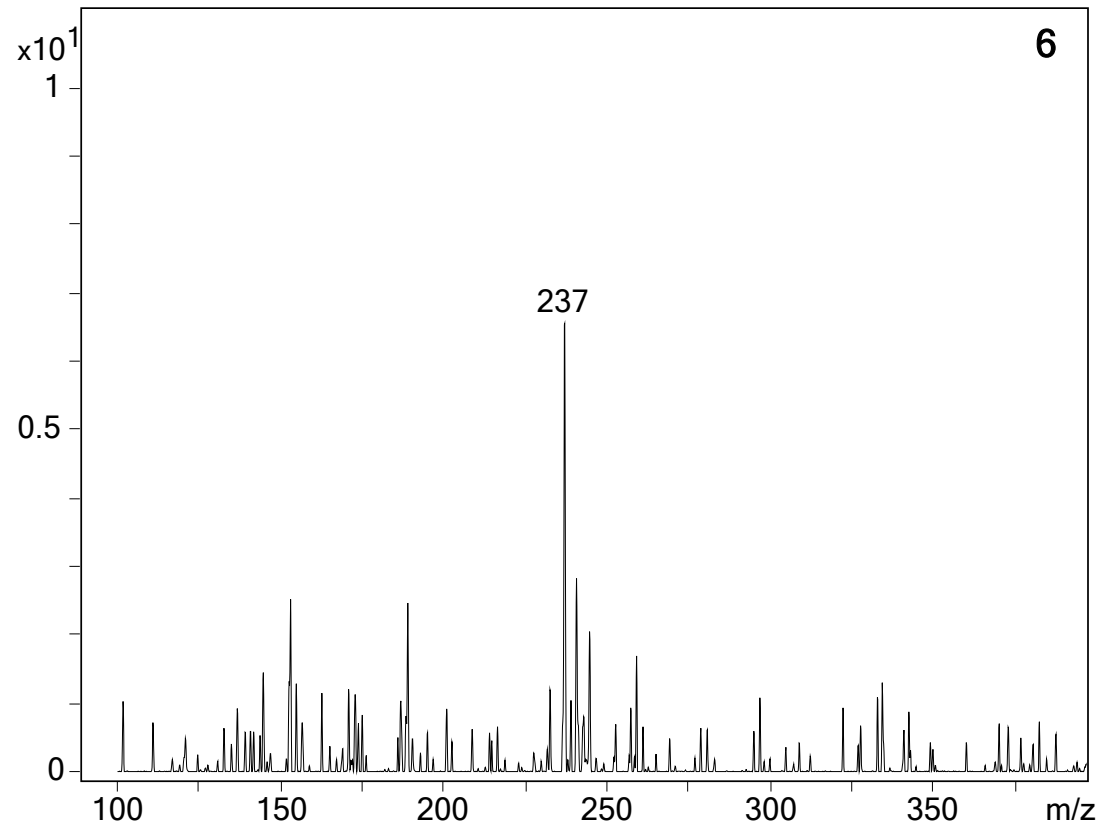


Figure S7: ESI--MS mass spectra of compound 7 identified in L. longiflorum.

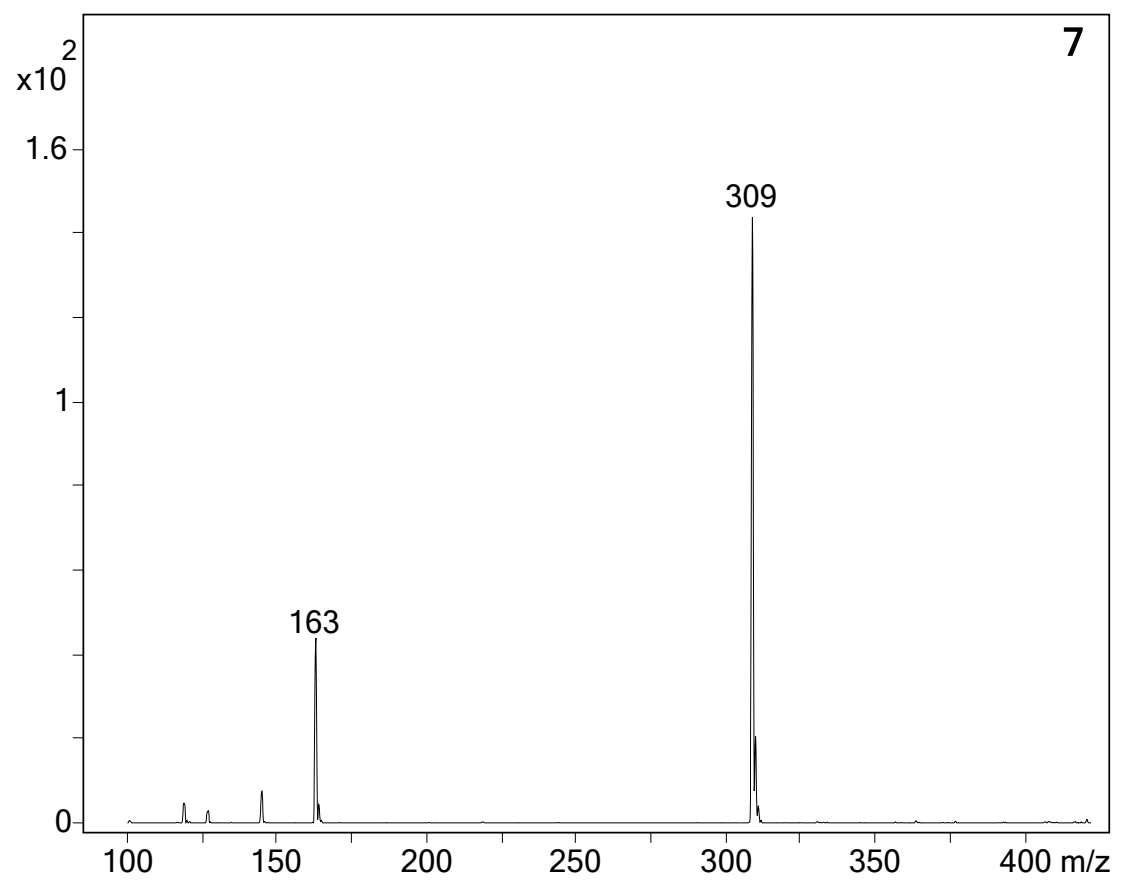


Figure S8: ESI--MS mass spectra of compound 8 identified in L. longiflorum.

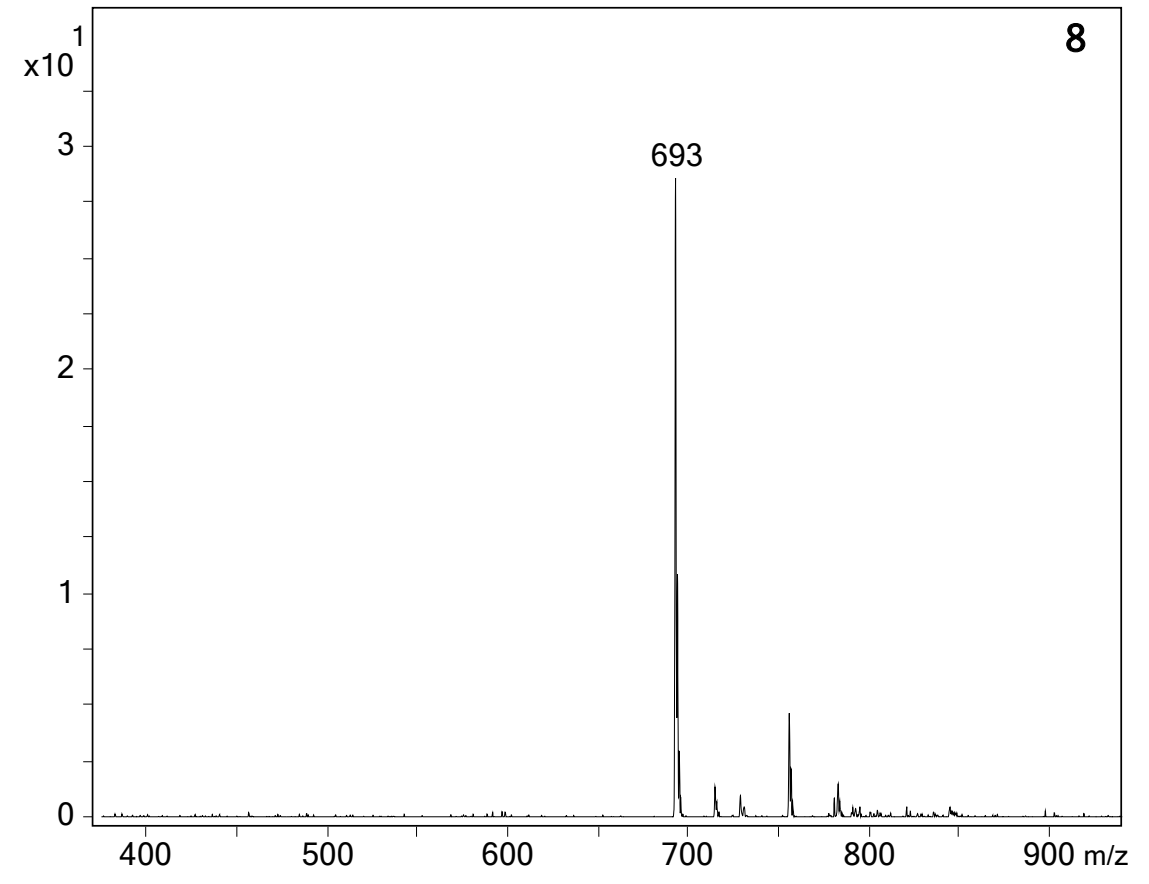


Figure S9: ESI--MS mass spectra of compound 9 identified in L. longiflorum.

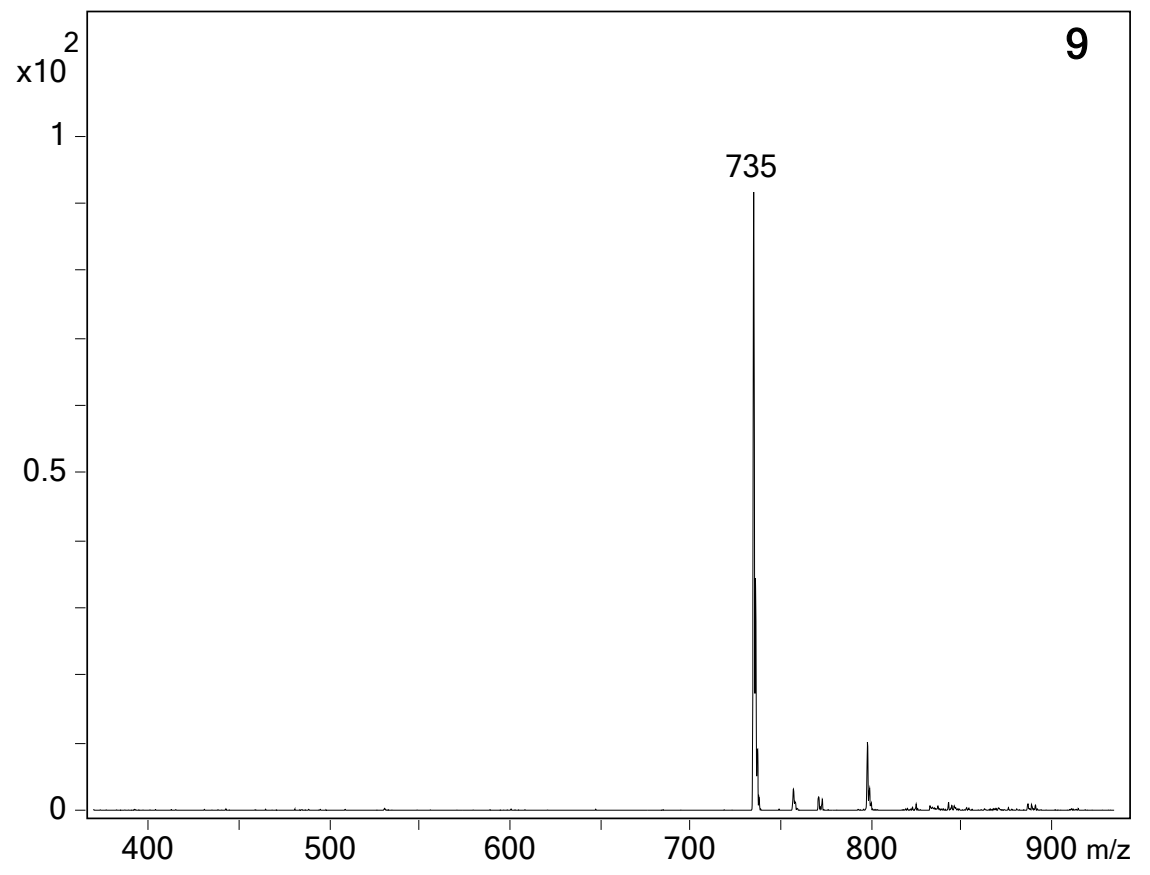

